九州大学学術情報リポジトリ

Kyushu University Institutional Repository

\title{
Characterization of Biochar Derived from Three Types of Biomass
}

Oh, Taek-Keun

Biotron Application Center, Kyushu University

Choi, BongSu

National Ecological Institute Planning Office

Shinogi, Yoshiyuki

Science for Bioproduction Environment, Faculty of Agriculture, Kyushu University

Chikushi, Jiro

九州大学生物環境調節センター

https://doi.org/10.5109/22049

出版情報：九州大学大学院農学研究院紀要. 57 (1)，pp.61-66，2012-02. Faculty of Agriculture， Kyushu University

バージョン:

権利関係： 


\title{
Characterization of Biochar Derived from Three Types of Biomass
}

\author{
Taek-Keun $\mathrm{OH}^{1, *, \dagger}$, BongSu $\mathrm{CHOI}^{2, \dagger}$, Yoshiyuki SHINOGI ${ }^{3}$ \\ and Jiro CHIKUSHI ${ }^{1}$
}

\author{
Biotron Application Center, Kyushu University, Hakozaki, 6-10-1, Fukuoka 812-8581, Japan
}

(Received October 31, 2011 and accepted November 9, 2011)

\begin{abstract}
We examined the physico-chemical properties of the biochar produced from orange peel, residual wood, and water treatment sludge at different pyrolytic temperatures from 300 to $700^{\circ} \mathrm{C}$. In the peel biochar (OPB) and wood biochar (RWB), $\mathrm{pH}$ and carbon content tended to increase with increasing pyrolytic temperature and were higher than those in the sludge biochar (WSB). The electrical conductivity of the OPB was the highest, while specific surface area of the RWB was the highest among the three types of biochar. The specific surface area was relatively high in any biochar. Any biochar surface displayed by scanningelectron-micrographs revealed many hollow channels and very heterogeneous forms. Unlike the WSB, surface functional groups of the OPB and RWB were similar in intensity and shape. From characteristic results of $\mathrm{pH}$, specific surface area, and functional groups, the biochar derived from orange peel, residual wood, and water treatment sludge may have a possibility to be used as an environmental-cost effective soil amendment and adsorbent.
\end{abstract}

Key words: Biochar, Biomass, Pyrolysis

\section{INTRODUCTION}

A wide variety of biomass have been generated in agricultural and industrial fields every year and the quantity of biomass may be continually increasing with the industrial development and the qualitative improvement of human life. For example, on a global scale, approximately 67.6 million tons of the oranges are produced in 2009 (FAOSTAT) and the large amount of orange waste composed of peels and membrane residues are generated by the juice producing process. In another case, an astonishing amount of 10,000 tons per day of water treatment sludge is also produced in drinking-water treatment processes (Dharmappa et al., 1997). Due to a significant increase of various biomass, the practical management and the safe disposal method have been becoming one of the main environmental concerns throughout the world.

A number of scientists have been attempting to solve these problems of the increasing biomass and many studies have been made to reuse the biomass on the basis of raw material properties. For examples, the components of the orange peel such as cellulose, pectin, hemicelluloses, and lignin were found to contain many functional groups of hydroxyl and carboxyl, which improve the cation exchange capacity and make a potential adsorbent in aqueous solution (Li et al., 2008; Liang et al., 2010). In addition, the application of the orange peel

\footnotetext{
Biotron Application Center, Kyushu University, Hakozaki 6-101, Higashi-ku, Fukuoka city 812-8581, Japan

National Ecological Institute Planning Office, Gwacheon, Gyeonggi, 427-800, Korea

Science for Bioproduction Environment, Faculty of Agriculture, Kyushu University, Hakozaki 6-10-1, Higashi-ku, Fukuoka city 812-8581, Japan

These two authors contributed equally to this work and should be considered co-first authors

* Corresponding author (E-mail: otgwins@agr.kyushu-u.ac.jp)
}

waste to soil has enhanced the productivity because this application increased the quantities of organic matter, nitrogen, phosphorous, and potassium in the soil (Correia Guerrero et al., 1995). Food-industrial waste sludge is also considered as reusable biomass because the sludge has a high organic matter content and phosphorous adsorption coefficient, a wide range of micronutrients, and macronutrients (Aggelides and Londra, 2000; Elliott and Dempsey, 1991; Ippolito et al., 2003; Logan and Harrison, 1995). Furthermore, the water treatment sludge can be used as soil amendment because the sludge has less toxic substances, such as heavy metal and pathogens, compared with sewage sludge (Dayton and Basta, 2001; Elliott and Dempsey, 1991, Oh et al., 2010).

For more effective management and disposal of the biomass, pyrolysis of the biomass has been promoted as an alternative way of managing a range of organic wastes in recent years (Shinogi and Kanri, 2003) because this process can reduce weight, volume, and foul odor of biomass and make the product easier to handle (Shinogi et al., 2003). In particular, biochar produced through pyrolysis processing under limited oxygen condition has drawn a lot of attention as a useful material from many researchers. Due to carbon-enriched and porous properties, the biochar has been studied as a low-cost sorbent (Ioannidou and Zabaniotou, 2007), as a soil amendment to improve crop growth (Granatstein et al., 2009; Singh et al., 2010), and as a means of mitigating global warming by carbon sequestration (Glaser et al., 2002; Lehmann et al., 2006; Lehmann and Joseph, 2009; Steiner, 2007). However, numerous studies on the biochar focused on wood-derived biochar. Thus, more varied and detailed studies on the properties of the biochar are required to optimize the use of different biochar produced from a variety of biomass because the biochar properties depend upon both the nature of used biomass feedstock and the temperature conditions in pyrolytic process.

In the present study, orange peel, residual wood, and 
water treatment sludge were chosen as biomass feedstock for the biochar production. The basic analyses of physical and chemical properties on biochar prepared from these biomass at different pyrolytic temperatures were carried out to provide the basic information as to the potential application of the carbonized biomass materials to a specified field. Based on the information, we will discuss further more efficient reuse of the biochar.

\section{MATERIALS AND METHODS}

\section{Raw feedstock materials}

Three different types of biomass, i.e. orange peel (OP), residual wood (RW), and water treatment sludge (WS), were used in this study as raw feedstock for biochar preparation. The orange was available in a local fruit market located in Fukuoka Prefecture, Japan, and the peels were stripped with a paring knife. For easy storage and management, the OP was washed with distilled water three times to remove dusts and then was cut into small pieces with the sizes larger than $1 \mathrm{~cm}^{2}$. The RW was collected from a dump site in Kyushu University, Japan, and then was washed with distilled water. We also collected the WS, in which PAC (polyaluminium chloride) is used as coagulant, from Tatara drinking-water treatment plants located in Fukuoka Prefecture, Japan. These collected OP, RW, and WS were air-dried at room temperature for 3 days and subsequently oven-dried overnight at $75 \pm 5^{\circ} \mathrm{C}$. The oven-dried feedstock were used for biochar production via pyrolysis under oxygen-limited conditions at various temperatures ranging from 300 to $700^{\circ} \mathrm{C}$.

\section{Biochar preparation}

Biochar was produced by pyrolyzing process of oven-dried feedstock. The process of the production was briefly described as follows: First, the each feedstock was placed into a stainless steel dish in a muffle furnace (FM48, Yamaha, Japan), covered with fitting lid to restrict the access of air during carbonization, which allows the material to be charred rather than combusted (Chen et al., 2008) and then pyrolyzed for 2 hours at different temperatures of $300,400,500,600$, and $700^{\circ} \mathrm{C}$. The resulting biochar was crushed and sieved into less than 2-mm size and stored for the following experiments in air-tight containers. For comparison, the oven-dried feedstock passed through 2-mm size sieve was also used in the experiments. In this paper, the prepared biochar is denoted by $\mathrm{OPB}_{\mathrm{xxx}}$, $\mathrm{RWB}_{\mathrm{xxx}}$, or $\mathrm{WSB}_{\mathrm{xxx}}$ for the OP bio- char, RW biochar, or WS biochar, respectively, treated at the pyrolyzing temperature $\mathrm{xxx}^{\circ} \mathrm{C}$.

\section{Characterization of Samples}

Physical and chemical analyses were further conducted to provide basic properties of both raw feedstock and biochar. Electrical conductivity (EC) and $\mathrm{pH}$ of the feedstock and the biochar were measured in 1:10 (samples : distilled water) using a EC meter (B-173, HORIBA, Japan) and pH meter (F-21, HORIBA, Japan), respectively. Carbon, hydrogen, and nitrogen composition measurements were conducted using an elemental analyzer (Yanaco CHN Corder MT-5, Japan). The oxygen content was determined by a mass balance. Yields of biochar produced from the three types of biomass feedstock were investigated for only the sample heated at $900^{\circ} \mathrm{C}$ for 4 hours, where the yield is defined as the ratio of the biochar weight after pyrolysis process to the initial weight of the feedstock. Chemical composition involved in the three types of feedstock was analysed by X-ray fluorescence (XRF) spectrometry (EDX-800, Shimadzu, Japan). Total specific surface area (SSA) of samples was determined using the Ethylene Glycol Monoethyl Ether (EGME) method described by Cerato and Lutenegger (2002). Heavy metal contents in the feedstock were measured by inductively coupled plasma-optical emission spectrophotometer (ICP-OES, varian 730-ES, USA). Functional groups were identified by the Fouriertransform infrared spectroscopy (FT/IR-620). The FT-IR spectra were collected with a spectrometer using potassium bromide $(\mathrm{KBr})$ pellets and the wavenumber ranging from 400 to $4000 \mathrm{~cm}^{-1}$. Surface morphology was identified by scanning electron microscopy (SEM; SS-550, Shimadzu, Japan). All the FT-IR, SEM, and EDX analyses were performed in the Analytical Center of Kyushu University.

\section{RESULTS AND DISCUSSION}

\section{Characteristics of the prepared each feedstock}

The measured results showed different characteristics between the types of biomass feedstock (Table 1 and 2). The $\mathrm{pH}$ of the $\mathrm{OP}, \mathrm{RW}$, and WS was $\mathrm{pH} 4.1, \mathrm{pH}$ 6.2 , and $\mathrm{pH} 5.7$, respectively (Table 1 ). The RW had higher specific surface area $\left(291.3 \mathrm{~m}^{2} \mathrm{~g}^{-1}\right)$ and $\mathrm{C} / \mathrm{N}$ ratio (163.5) than the OP and WS. Compared to the WS, the $\mathrm{OP}$ and RW were carbon rich and had carbon content about $42 \%$ and $46 \%$, respectively, being confirmed that agricultural and wood residues such as the OP and RW

Table 1. Physico-chemical properties of orange peel, residual wood, and water treatment sludge used as feedstock

\begin{tabular}{|c|c|c|c|c|c|c|c|c|c|c|c|}
\hline \multirow{2}{*}{ Feedstock } & \multirow{2}{*}{$\begin{array}{c}\mathrm{pH} \\
(1: 10)\end{array}$} & \multirow{2}{*}{$\begin{array}{c}\mathrm{EC} \\
\left(\mathrm{S} \mathrm{m}^{-1}\right)\end{array}$} & \multirow{2}{*}{$\begin{array}{c}\text { SSA } \\
\left(\mathrm{m}^{2} \mathrm{~g}^{-1}\right)\end{array}$} & \multicolumn{5}{|c|}{ Element content (\%) } & \multicolumn{3}{|c|}{ Atomic ratios } \\
\hline & & & & $\mathrm{C}$ & $\mathrm{H}$ & $\mathrm{N}$ & $\mathrm{O}$ & Ash & $\mathrm{O} / \mathrm{C}$ & $\mathrm{H} / \mathrm{C}$ & $(\mathrm{O}+\mathrm{N}) / \mathrm{C}$ \\
\hline $\mathrm{OP}$ & 4.1 & 1.7 & 24.0 & 41.8 & 6.4 & 1.0 & 47.9 & 2.9 & 0.9 & 1.8 & 0.9 \\
\hline RW & 6.2 & 2.0 & 291.3 & 45.8 & 6.1 & 0.3 & 44.0 & 3.8 & 0.7 & 1.6 & 0.7 \\
\hline WS & 5.7 & 1.3 & 93.5 & 6.6 & 1.8 & 0.3 & 15.3 & 76.0 & 1.7 & 3.2 & 1.8 \\
\hline
\end{tabular}

Abbreviations: EC, electrical conductivity; SSA, specific surface area 
Table 2. Principal chemical compositions of orange peel, residual wood, and water treatment sludge used as feedstock

(Unit: wt\%)

\begin{tabular}{cccccccccccc}
\hline Feedstock & $\mathrm{SiO}_{2}$ & $\mathrm{Al}_{2} \mathrm{O}_{3}$ & $\mathrm{Fe}_{2} \mathrm{O}_{3}$ & $\mathrm{CaO}$ & $\mathrm{K}_{2} \mathrm{O}$ & $\mathrm{TiO}_{2}$ & $\mathrm{SO}_{3}$ & $\mathrm{P}_{2} \mathrm{O}_{5}$ & $\mathrm{MnO}$ & $\mathrm{SrO}$ & $\mathrm{Total}$ \\
\hline $\mathrm{OP}$ & - & - & 1.0 & 66.1 & 28.4 & - & 2.8 & 1.7 & - & - & 100.0 \\
$\mathrm{RW}$ & 3.0 & - & 2.8 & 84.8 & 5.8 & - & 1.8 & 1.5 & - & 0.3 & 100.0 \\
WS & 40.0 & 49.9 & 5.6 & 1.4 & 1.4 & 0.6 & 0.4 & 0.4 & 0.3 & - & 100.0
\end{tabular}

Table 3. Heavy metal concentrations of each feedstock used for experiments and maximum allowable limits

(Unit : $\mathrm{mg} \mathrm{kg}^{-1}$ )

\begin{tabular}{|c|c|c|c|c|c|c|c|}
\hline \multirow{2}{*}{ Heavy metals } & \multirow{2}{*}{$\mathrm{OP}$} & \multirow{2}{*}{ RW } & \multirow{2}{*}{ WS } & \multirow{2}{*}{$\mathrm{SS}^{\dagger}$} & \multirow{2}{*}{$\mathrm{SSB}^{\dagger}$} & \multicolumn{2}{|c|}{ Maximum allowable limits } \\
\hline & & & & & & Japan $^{\ddagger}$ & U. S. ${ }^{8, q}$ \\
\hline Arsenic (As) & n.d. & n.d. & 9.5 & $3-5$ & 2 & 50 & $75^{8}$ \\
\hline Cadmium (Cd) & n.d. & n.d. & 0.3 & $2-7$ & 3 & 5 & $85^{\S}$ \\
\hline Chromium (Cr) & 3.3 & 4.8 & 10.9 & $40-400$ & 80 & 500 & $3000^{\pi}$ \\
\hline Copper (Cu) & 5.6 & 11.5 & 26.5 & $1,000-2,200$ & 2,600 & - & $4300^{\S}$ \\
\hline Lead (Pb) & n.d. & n.d. & 8.5 & $30-150$ & 5 & 100 & $840^{\S}$ \\
\hline Nickel (Ni) & 2.4 & 1.7 & 7.5 & $20-100$ & 35 & 300 & $420^{\S}$ \\
\hline Zinc (Zn) & n.d. & n.d. & 41.8 & $640-1,900$ & 1,700 & - & $2500^{\S}$ \\
\hline
\end{tabular}

†'source : Bridle and Pritchard (2004), SS : Sewage sludge biosolids (wet cake), SSB : Sewage sludge biochar

${ }^{\ddagger}$ source Andreoli et al. (2008).

${ }^{\S}$ source : Adapted from U.S. EPA (1995)

CCL (ceiling concentration limits) = maximum concentration permitted for land application

ף. source : Colorado Department of Health. Biosolids Regulation 4.9.0. (1996)

n.d. : not detected

can be used as proper feedstock for biochar production. The OP and RW contain predominantly calcium and potassium oxides with measurable levels of sulfur, iron, and phosphorus oxides (Table 2). The WS contained mainly oxides of aluminum, silica, and iron. In particular, a significant concentration of aluminum oxide in the WS might occur because of coagulant added in water treatment processes. These oxides contained in the WS in the aqueous medium would be hydroxylated to develop surface charge and have a high capacity as adsorbent.

In the present experiment, we also investigated heavy metal concentrations of OP, RW, and WS used as the feedstock. We detected $\mathrm{Cr}, \mathrm{Cu}$, and $\mathrm{Ni}$ in the $\mathrm{OP}$ and $\mathrm{RW}$ and $\mathrm{As}, \mathrm{Cd}, \mathrm{Cr}, \mathrm{Cu}, \mathrm{Pb}, \mathrm{Ni}$, and $\mathrm{Zn}$ in the WS, but not so significant, being lesser than the maximum allowable limits of Japan and the US standards (Table 3). It means that any biochar produced from the OP, RW, and WS can be safely used as agricultural purposes such as soil amendment. According to Bridle and Pritchard (2004), on the other hand, high contents of heavy metals have been reported in biochar produced from sewage sludge (Table 3). Muralidhara (1982) also reported very high concentration of chromium in a biochar produced from tannery wastes. Thus, before making the biochar, more detailed investigation of using feedstock is needed to ensure the safe use of various biochar as soil amendments in agriculture.

\section{Characteristics of the prepared biochar}

The measured results showed different characteristics between the biochar produced from the three types of feedstock at pyrolytic temperatures ranging from 300 to $700^{\circ} \mathrm{C}$. The yield of biochar is highly dependent upon the pyrolysis conditions such as temperature, heating rate, and heating time (Demirbas and Arin, 2002; Tsai et al., 2007; Uzun et al., 2006; Williams and Besler, 1996). In the present experiment, when the pyrolytic temperature increased from 300 to $700^{\circ} \mathrm{C}$, the yields for OPB, RWB, and WSB significantly decreased from 56.7 to $30.0 \%$, from 53.9 to $30.5 \%$, and from 89.7 to $83.0 \%$, respectively (Fig. 1). The yields of OPB and RWB were lower in comparison with the WSB and significantly decreased during 300 to $400^{\circ} \mathrm{C}$. It might be due to the destruction of chemical constituents, such as cellulose and hemicelluloses, included in OP and RW. These

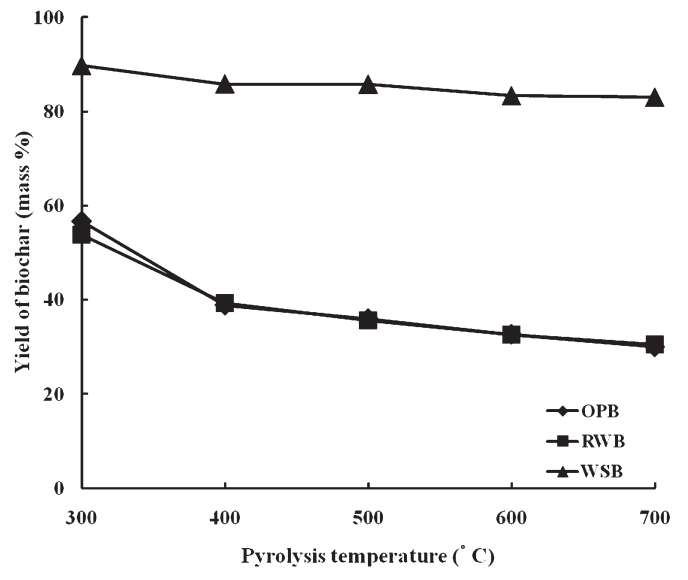

Fig. 1. Yields of biochar derived from each feedstock sample on pyrolysis temperature. 
results accorded with the observation by Shinogi and Kanri (2003), who indicated a significant decrease of the yield during 200 to $400^{\circ} \mathrm{C}$ for bagasse and rice husk. Thus, the production of biochar through pyrolytic process can be an effective way to reduce the volume of the waste biomass.

Scanning electron micrographs (SEM) images are very useful to obtain accurate details about surface structure of biochar. The comparison of the images between biochar and their raw feedstock might then allow us to understand morphological changes during the carbonization stage (Özçimen and Ersoy-Meriçboyu, 2010). The SEM pictures of feedstock and the biochar produced at $600^{\circ} \mathrm{C}$ are given in Fig. 2. The surfaces of $\mathrm{OPB}_{600}$ and $\mathrm{RWB}_{600}$ were imaged with many hollow channels in diameters of around 10 to 20 micrometers. These porous structures of the OPB and RWB are likely to provide a high internal surface area, adsorption ability for soluble organic matter and inorganic nutrients, and suitable habitat for microbes such as bacteria and arbuscular mycorrhizal fungi. Unlike the OPB and RWB, the WSB was composed of very coarse and heterogeneous surfaces and significantly irregular forms and sizes of the particles in the SEM. The structural difference may reflect the specific surface area and the adsorption capacity as environmental and cost-effective adsorbent for nutrients or pollutants.

The physical and chemical properties of the biochar samples produced under different pyrolytic temperatures are shown in Table 4. As pyrolytic temperature increased from 300 to $700^{\circ} \mathrm{C}, \mathrm{pH}$ increased from 8.0 to 12.3 for the $\mathrm{OPB}$, from 7.8 to 10.3 for the RWB, and from 5.8 to 6.8 for the WSB, respectively. These results were similar to those of Lehmann (2007), in which biochar can be produced with any $\mathrm{pH}$ between 4.0 and 12.0 and the $\mathrm{pH}$ of fresh biochar tends to increase with increasing of production temperature. Thus, the biochar of biomass feedstock investigated can be employed as a soil amendment to increase soil pH in acidic soils occupying approximately $30 \%$ of the total arable land on the earth (Yuan et al., 2011).

The SSA that is one of the important parameters to evaluate adsorption is involved in the distribution of pore structure (Shinogi and Kanri, 2003). In the present study, we confirmed that the highest SSA were $428.0 \mathrm{~m}^{2}$ $\mathrm{g}^{-1}$ for $\mathrm{OPB}_{400}, 629.0 \mathrm{~m}^{2} \mathrm{~g}^{-1}$ for $\mathrm{RWB}_{300}$, and $135.2 \mathrm{~m}^{2} \mathrm{~g}^{-1}$ for $\mathrm{WSB}_{700}$, respectively (Table 4). Thus, the SSA of RWB was larger than that of OPB or WSB. The changes in SSA with pyrolytic temperature were inconsistent with the previous reports (Cao and Harris, 2010; Chen et al., 2008; Shinogi and Kanri, 2003), in which the surface area of biochar generally increases with increasing treatment temperature. However, the high SSA measured suggests that the biochar derived from OP, RW, and WS can be expected to be reusable as effective substitute for chemical agent adsorbing nutrient, water, air or pollutant such as heavy metals.

The elemental content changes in $\mathrm{C}, \mathrm{H}, \mathrm{O}$, and $\mathrm{N}$ and their associated ratios, which indicate maturation degree of biochar, were also listed in Table 4. As expected in the pyrolytic process for the biochar derived from OP and RW, the $\mathrm{C}$ content increased, while the $\mathrm{H}$ and $\mathrm{O}$ contents decreased with increasing pyrolytic temperature. The $\mathrm{O} / \mathrm{C}$ and $\mathrm{H} / \mathrm{C}$ ratios for all biochar samples tended to be the highest in the lowest temperature and decreased with increase in temperature. In addition, the $(\mathrm{O}+\mathrm{N}) / \mathrm{C}$,
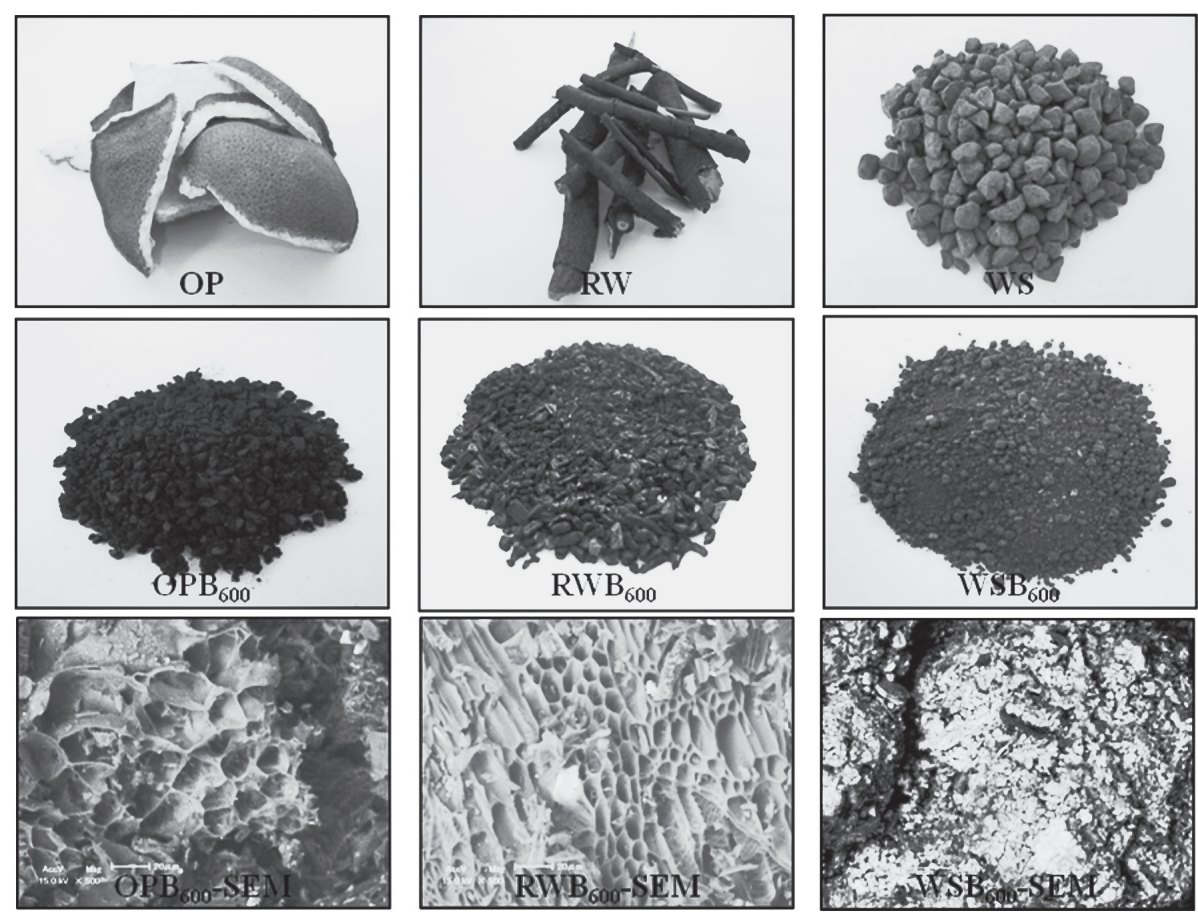

Fig. 2. Pictures of feedstock, biochar and scanning electron micrographs (SEM) of biochar derived from each feedstock.

Conditions : pyrolyzing temperature $600^{\circ} \mathrm{C}$, size of biochar samples $<2.0 \mathrm{~mm}$, magnification of SEM analysis $\times 500$ 
Table 4. Physico-chemical properties of the each biochar prepared under different pyrolytic temperatures

\begin{tabular}{|c|c|c|c|c|c|c|c|c|c|c|c|}
\hline \multirow{2}{*}{ Treatments } & \multirow{2}{*}{$\begin{array}{c}\mathrm{pH} \\
(1: 10)\end{array}$} & \multirow{2}{*}{$\begin{array}{c}\mathrm{EC} \\
\left(\mathrm{S} \mathrm{m}^{-1}\right)\end{array}$} & \multirow{2}{*}{$\begin{array}{c}\text { SSA } \\
\left(\mathrm{m}^{2} \mathrm{~g}^{-1}\right)\end{array}$} & \multicolumn{5}{|c|}{ Element content (\%) } & \multicolumn{3}{|c|}{ Atomic ratios } \\
\hline & & & & $\mathrm{C}$ & $\mathrm{H}$ & $\mathrm{N}$ & $\mathrm{O}$ & Ash & $\mathrm{O} / \mathrm{C}$ & $\mathrm{H} / \mathrm{C}$ & $(\mathrm{O}+\mathrm{N}) / \mathrm{C}$ \\
\hline OPB300 & 8.0 & 1.2 & 51.2 & 60.4 & 5.2 & 1.6 & 28.9 & 3.9 & 0.4 & 1.0 & 0.4 \\
\hline OPB400 & 11.6 & 2.1 & 428.0 & 68.4 & 4.8 & 2.0 & 19.8 & 5.0 & 0.2 & 0.8 & 0.2 \\
\hline OPB500 & 12.1 & 5.1 & 113.8 & 71.0 & 3.2 & 1.9 & 17.1 & 6.8 & 0.2 & 0.5 & 0.2 \\
\hline OPB600 & 12.1 & 5.6 & 137.1 & 74.7 & 2.1 & 1.7 & 13.4 & 8.1 & 0.1 & 0.3 & 0.2 \\
\hline OPB700 & 12.3 & 7.2 & 110.2 & 74.8 & 1.6 & 1.7 & 13.4 & 8.5 & 0.1 & 0.3 & 0.2 \\
\hline RWB300 & 7.8 & 0.5 & 629.0 & 62.1 & 4.4 & 0.9 & 24.8 & 7.8 & 0.3 & 0.8 & 0.3 \\
\hline RWB400 & 10.0 & 0.6 & 208.8 & 68.1 & 3.3 & 0.7 & 19.4 & 8.5 & 0.2 & 0.6 & 0.2 \\
\hline RWB500 & 10.0 & 0.8 & 227.1 & 69.7 & 2.8 & 0.7 & 17.6 & 9.2 & 0.2 & 0.5 & 0.2 \\
\hline RWB600 & 10.3 & 1.4 & 210.3 & 74.6 & 1.7 & 0.7 & 11.9 & 11.1 & 0.1 & 0.3 & 0.1 \\
\hline RWB700 & 10.3 & 1.7 & 186.7 & 78.4 & 2.4 & 0.7 & 5.9 & 12.6 & 0.1 & 0.4 & 0.1 \\
\hline WSB300 & 5.8 & 0.8 & 120.3 & 8.8 & 1.4 & 0.4 & 7.3 & 82.1 & 0.6 & 1.9 & 0.7 \\
\hline WSB400 & 6.4 & 0.6 & 126.4 & 8.5 & 1.0 & 0.3 & 6.4 & 83.8 & 0.6 & 1.5 & 0.6 \\
\hline WSB500 & 6.6 & 0.4 & 112.9 & 7.8 & 0.9 & 0.2 & 5.4 & 85.7 & 0.5 & 1.3 & 0.6 \\
\hline WSB600 & 6.6 & 0.4 & 114.4 & 8.4 & 0.6 & 0.2 & 2.0 & 88.8 & 0.2 & 0.9 & 0.2 \\
\hline WSB700 & 6.8 & 0.3 & 135.2 & 8.1 & 0.5 & 0.2 & 0.6 & 90.6 & 0.1 & 0.8 & 0.1 \\
\hline
\end{tabular}

${ }^{\dagger}$ Abbreviations: SSA, specific surface area; H/C: atomic ratio of hydrogen to carbon; O/C: atomic ratio of oxygen to carbon.

which means polarity index, also decreased with increasing the pyrolytic temperature and the decrease indicates a reduction of the surface polar functional groups (Chen and Chen, 2009). According to Novak et al. (2009), this property is a typical feedstock response in the pyrolytic process, where the feedstock loses surface functional $\mathrm{OH}$ groups due to dehydration and loses $\mathrm{C}$ bound to $\mathrm{O}$ and $\mathrm{H}$ atoms at higher temperatures due to structural core degradation.

Differences in infrared spectra are reflected by water loss, organic matter combustion, and an increase of mineral component ratio resulted from heat-induced mass loss (Cao and Harris, 2010). Thus, we also investigated the functional groups indentified from the FT-IR spectra for the three types of feedstock and biochar samples (Fig. 3). The spectra of OP and OPB demonstrated many bands at $3440 \mathrm{~cm}^{-1}(\mathrm{O}-\mathrm{H}), 2915 \mathrm{~cm}^{-1}(\mathrm{C}-\mathrm{H})$, $2364 \mathrm{~cm}^{-1} \quad\left(\mathrm{CO}_{2}\right), 1730 \mathrm{~cm}^{-1} \quad(\mathrm{C}=\mathrm{O}), 1630 \mathrm{~cm}^{-1} \quad(\mathrm{C}=\mathrm{C})$, $1420 \mathrm{~cm}^{-1}$ (aliphatic and aromatic groups), and $1080 \mathrm{~cm}^{-1}$ (C-O). Absorption of the bands decreased with increasing pyrolytic temperature as expected. The spectra of RW and RWB were similar to those of OP and OPB in intensity and shape. This may be caused by similarity of constituents between two types of raw feedstock (i.e. $\mathrm{OP}$ and RW), such as cellulose, hemicelluloses, pectin, and lignin. However, the two peaks at around $2840 \mathrm{~cm}^{-1}$ and $2765 \mathrm{~cm}^{-1}$ corresponding to $\mathrm{CH}_{3}$ were present only in the raw RW sample. In the WS and WSB spectra, the relatively broad band occurred in 3690 to $3450 \mathrm{~cm}^{-1}$ range due to $\mathrm{O}-\mathrm{H}$ stretching in -OH groups. The ranges of 2375 to $2348 \mathrm{~cm}^{-1}$ and 1085 to $1040 \mathrm{~cm}^{-1}$ are associated with $\mathrm{CO}_{2}$ and $\mathrm{C}-\mathrm{O}$, respectively. The bands below $600 \mathrm{~cm}^{-1}$ are due to metal-halogen stretching vibrations in both organic and inorganic halogens compounds (Hossain et al., 2011). It was also seen that some peaks disappeared after the pyrolysis treatment at different temperatures. The presence of functional groups such as the carboxyl and hydroxyl groups suggest that all these biochar could

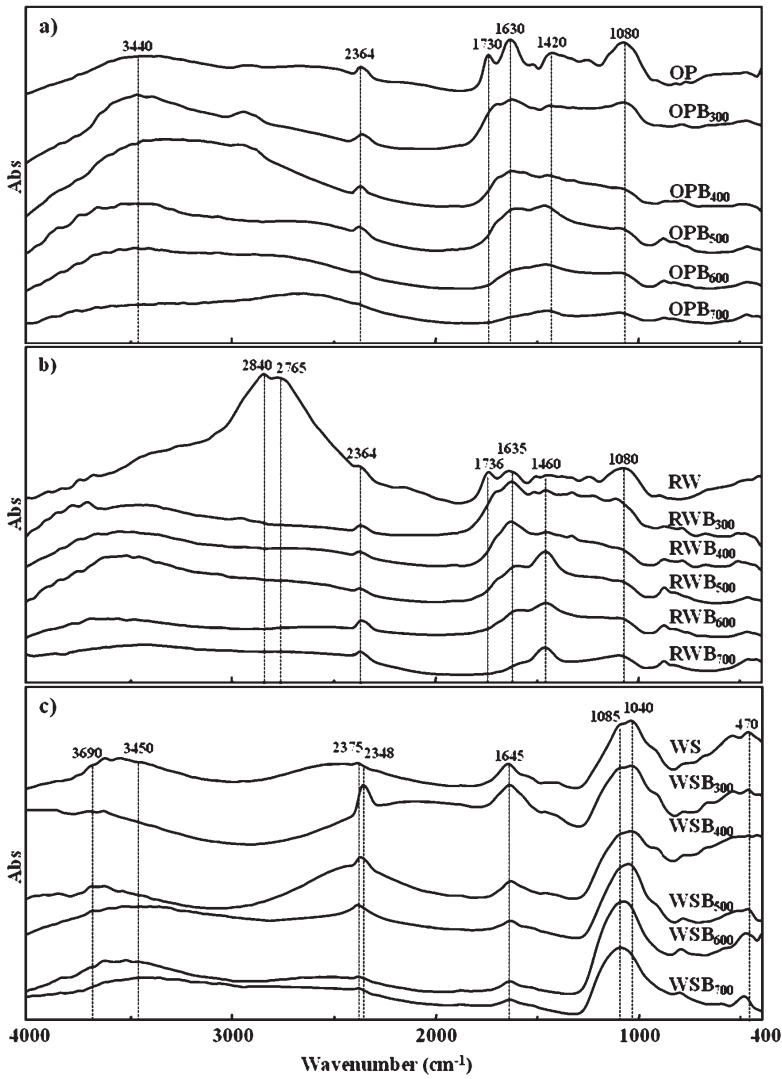

Fig. 3. Fourier-transform infrared spectroscopy (FT-IR) changes of feedstock and biochar produced from each feedstock. (a: OP and $\mathrm{OPB}_{\mathrm{xxx}}$, b: RW and $\mathrm{RWB}_{\mathrm{xxx}}$, WS and $\mathrm{WSB}_{\mathrm{xxx}}$ ). 
have a possibility to be used as a soil amendment for improving of the cation exchange capacity and a potential adsorbent.

\section{CONCLUSIONS}

This study was carried out to provide basic information as to the possibility of reuse of biochar derived from different biomass. The experimental results clearly show that pyrolytic temperature and feedstock type have significant effect on the physic-chemical properties of the biochar. Reduction of waste-biomass volume through pyrolytic process also means that the use of biochar may provide possible way to solve the major problem such as management and disposal of the waste biomass. The biochar production from biomass such as orange peel, residual wood, and water treatment sludge may be an effective way for recycling the waste resources.

\section{REFERENCES}

Aggelides S. M. and P. A. Londra 2000 Effects of compost produced from town wastes and sewage sludge on the physical properties of a loamy and clay soil. Bioresour. Technol., 71(3): 253-259

Bridle T. R. and D. Pritchard 2004 Energy and nutrient recovery from sewage sludge via pyrolysis. Water Sci. Technol., 50: $169-175$

Cao X. and W. Harris 2010 Properties of dairy-manure-derived biochar pertinent to its potential use in remediation. Bioresour. Technol., 101: 5222-5228

Cerato A. B. and A. J. Lutenegger 2002 Determination of Surface Area of Fine-Grained Soils by the Ethylene Glycol Monoethyl Ether (EGME) Method. Geotechnical Testing J., ASTM 25(3): 315-321

Chen B. and Z. Chen 2009 Sorption of naphthalene and 1-naphthol by biochars of orange peels with different pyrolytic temperatures. Chemosphere, 76: 127-133

Chen B., D. Zhou and L. Zhu 2008 Transitional adsorption and partition of nonpolar and polar aromatic contaminants by biochars of pine needles with different pyrolytic temperatures. Environ. Sci. Technol., 42: 5137-5143

Correia Guerrero C., J. Carrasco de Brito, Nuno Lapa and J. F. Santos Oliveira 1995 Re-use of industrial orange wastes as organic fertilizers. Bioresour. Technol., 53: 43-51

Dayton E. A. and N. T. Basta 2001 Characterization of drinking water treatment residuals for use as a soil substitute. Water Environ. Res., $\mathbf{7 3}(1)$ : 52-57

Demirbas A. and G. Arin 2002 An overview of biomass pyrolysis. Eng. Sources, 24: 471-482

Dharmappa H. B., A. Hasia and P. Hagare 1997 Water treatment plant residuals management. Water Sci. Technol., 35(8): $45-56$

Elliott H. A. and B. A. Dempsey 1991 Agronomic effects of land application of water treatment sludge. J. Am. Water Works Assoc., 83: 126-131

FAOSTAT (Food Agriculture Organization of the United Nations, Statistical Database), Production (2009). [Online]. Available: http://faostat.fao.org/ [15 October 2011]

Glaser B 2007 Prehistorically modified soils of central Amazonia: a model for sustainable agriculture in the twenty-first century. Philos. Trans. R. Soc. Lond. B. Biol. Sci., 362: 187-196

Glaser B., J. Lehmann and W. Zech 2002 Ameliorating physical and chemical properties of highly weathered soils in the tropics with charcoal - a review. Biol. Fertil. Soils, 35: 219-230

Granatstein D., C. E. Kruger, H. Collins, S. Galinato, M. GarciaPerez and J. Yoder 2009 Use of biochar from the pyrolysis of waste organic material as a soil amendment. Final project report, Center for Sustaining Agriculture and Natural Resources, Washington State Univ., Wenatchee, WA. 168pp

Hossain M. K., V. Strezov, K. Y. Chan, A, Ziolkowski and P. F. Nelson 2011 Influence of pyrolysis temperature on production and nutrient properties of wastewater sludge biochar. J. Environ. Manage., 92: 223-228

Ioannidou O. and A. Zabaniotou 2007 Agricultural residues as precursors for activated carbon production: A review. Renew. Sust. Eng. Rev., 11: 1966-2005

Ippolito J. A., F. A. Barbarick, D. N. Heil, J. P. Chandler and E. F. Redente 2003 Phosphorus retention mechanisms of a water treatment residual. J. Environ. Qual., 32: 1857-1864

Lehmann J. 2007 Bio-energy in the black. Frontiers in ecology and the environment, 5: 381-387

Lehmann J., J. Gaunt and M. Rondon 2006 Bio-char sequestration in terrestrial ecosystems-a review. Mit. Adapt. Strat. Global Change, 11: 403-427

Lehmann, J. and S. Joseph 2009 Biochar for Environmental Management: Science and Technology, in: Lehmann, J., Joseph, S. (Eds.), Earthscan Ltd, London, UK

Li X., Y. Tang, X. Cao, D. Lu, F. Luo and W. Shao 2008 Preparation and evaluation of orange peel cellulose adsorbents for effective removal of cadmium, zinc, cobalt and nikel. Colloids and Surfaces A: Physicochem. Eng. Aspects, 317: 512-521

Liang S., X. Guo, N. Feng and Q. Tian 2010 Isotherms, kinetics and thermodynamic studies of adsorption of $\mathrm{Cu}^{2+}$ from aqueous solutions by $\mathrm{Mg}^{2+} / \mathrm{K}^{+}$type orange peel adsorbents. $J$. Hazard. Mater., 174: 756-762

Logan T. J. and B. J. Harrison 1995 Physical characteristics of alkaline stabilized sewage sludge (N-Viro soil) and their effects on soil physical properties. J. Environ. Qual., 24: 153-164

Muralidhara H. S. 1982 Conversion of tannery waste to useful products. Resour. Conservation, 8: 43-59

Novak J. M., I. Kima, B. Xing, J. W. Gaskin, C. Steiner, K. C. Das, M. Ahmedna, D. Rehrah, D. W. Watts, W. J. Busscher and H. Schomberg 2009 Characterization of designer biochar produced at different temperatures and their effects on a loamy sand. Annals Environ. Sci., 3: 195-206

Oh T. K. and J. Chikushi 2010 Fluoride adsorption on water treatment sludge processed by polyaluminium chloride. J. Food, Agric. Environ., 54: 358-362

Oh T. K., K. Nakaji, J. Chikushi and S. K. Park 2010 Effect of the application of water treatment sludge on growth of lettuce (Lactuca satuva L.) and changes in soil properties. J. Fac. Agr., Kyushu Univ., 55(1): 15-20

Özçimen D. and A. Ersoy-Meriçboyu 2010 Characterization of biochar and bio-oil samples obtained from carbonization of various biomass materials. Renew. Energy., 35: 1319-1324

Singh B., B. P. Singh and A. L. Cowie 2010 Characterisation and evaluation of biochars for their application as a soil amendment. Aust. J. Soil Res., 48: 516-525

Shinogi Y. and Y. Kanri 2003 Pyrolysis of plant, animal and human waste: physical and chemical characterization of the pyrolytic products. Bioresour. Technol., 90: 241-247

Shinogi Y., Y. Yoshida, T. Koizumi, M. Yamaoka and T. Saito 2003 Basic characteristics of low-temperature carbon products from waste sludge. Advances in Environmental Research, 7: $661-665$

Tsai B. B., M. K. Lee and Y. M. Chang 2007 Fast pyrolysis of rice husk: Product yields and composition. Bioresour. Technol. 98: $22-28$

Uzun B. B., A. E. Putun, E. Putun 2006 Fast pyrolysis of soybean cake: Product yields and composition. Bioresour. Technol., 97: $569-576$

Williams P. T. and S. Besler 1996 The influence of temperature and heating rate on the slow pyrolysis of biomass. Renewable Eng., 7: 233-250

Yuan J. H., R. K. Xu and H. Zhang 2011 The forms of alkalis in the biochar produced from crop residues at different temperatures. Bioresour. Technol., 102: 3488-3497 